\title{
GPPS-BJ-2019-0096
}

\section{AN IMPROVED CONTROL METHOD OF RIM SEAL BASED ON AUXILIARY SEALING HOLES}

\author{
Ruonan Wang \\ Institute of Engineering Thermophysics, \\ Chinese Academy of Sciences \\ University of Chinese Academy of Sciences \\ wangruonan@iet.cn \\ Beijing, China
}

\author{
Guang Liu \\ Institute of Engineering Thermophysics, \\ Chinese Academy of Sciences \\ University of Chinese Academy of Sciences \\ liuguang@iet.cn \\ Beijing, China
}

\author{
Qiang Du \\ Institute of Engineering \\ Thermophysics, Chinese \\ Academy of Sciences \\ University of Chinese \\ Academy of Sciences \\ duqiang@iet.cn \\ Beijing, China
}

\author{
Zengyan Lian \\ Institute of Engineering \\ Thermophysics, Chinese \\ Academy of Sciences \\ University of Chinese \\ Academy of Sciences \\ lianzengyan@iet.cn \\ Beijing, China
}

\author{
Lei Xie \\ Institute of Engineering \\ Thermophysics, Chinese \\ Academy of Sciences \\ University of Chinese \\ Academy of Sciences \\ xielei@iet.cn \\ Beijing, China
}

\begin{abstract}
Purge flow is of great importance in cooling the rotorstator disc cavity and reducing hot gas ingestion in gas turbines. The amount of cooling air extracted from the compressor is crucial to engine efficiency. In order to simplify rim seal structure while ensuring high sealing efficiency, the current paper optimises the flow path of the secondary air system and present a new rim seal structure with auxiliary sealing holes transporting secondary sealing flow. The new structure is compared with the traditional one using CFD methods, showing that the sealing efficiency is improved by using inclined sealing holes. The depth of hot gas ingestion and the maximum pressure difference along circumference has been reduced. The current paper investigates the sealing efficiency under different inclined angle of auxiliary sealing hole $\left(0^{\circ}, 45^{\circ}\right)$ and flow distribution of sealing air (main sealing flow rate versus secondary sealing flow rate $=1: 1,2: 1,3: 1$ ), found that these two parameters both have important impacts on sealing efficiency. The relationship between these two factors and sealing efficiency has obtained, and it provides a new idea for the design of rim seal in gas turbines and aero engines.
\end{abstract}

\section{INTRODUCTION}

The mainstream hot gas may get into disk cavity through turbine rim in gas turbines. Hot gas ingestion may cause a lot of bad effects such as disk temperature increasing, disk core overheating and bearing damaging. Previous studies have shown that the life of the turbine disk can be reduced by $50 \%$ as long as the concentration of ingested gas has a certain increase in the disk cavity. In addition, the efficiency of the engine will increase by $0.5 \%$ and the fuel consumption will be reduced by $0.5 \%$ when the amount of cooling air cut in half (Scobie 2016). Therefore, the optimization goal of the rim seal is to achieve effective sealing with less sealing air in order to reduce the loss of thermal-power conversion and mixing between sealing flow and mainstream flow.

In order to improve the sealing efficiency, the widely used method is to provide a rim seal structure on the outer edge of the turbine disk to increase the flow resistance of hot gas and weaken the effect of tangential velocity of the mainstream. Sangan (Sangan 2012) used $\mathrm{CO}_{2}$ as a tracer gas to compare the sealing efficiencies of different rim seal structures, found that complex structure can improve sealing efficiency.

With the in-depth understanding of the flow mechanism of hot gas ingestion and the improvement of design and manufacture level, the current rim seal structure tends to be complicated. For example, Sangan (Sangan 2014) proposed a method by increasing the fin structure in the circumferential direction of the rim in order to increase the pressure of the external chamber near the rim, which can suppress hot gas ingestion. Scobie (Scobie 2016) proposed a rim seal structure with fins on the static disc side, and the minimum sealing mass flow rate $\Phi_{\min }$ can be reduced from 0.036 to 0.024 . Li ( $\mathrm{Li}$ 
2016) designed a hexagonal honeycomb along circumferential direction in the inner ring of the radial rim seal structure, which increases the turbulent dissipation of the axial velocity component, resulting in an increase in sealing efficiency of about $9 \% \sim 14 \%$.

Although the complex structure can improve the sealing efficiency, too complicated structure will cause problems such as difficulty in manufacture and scratch between components, which will reduce reliability and increase difficulty of maintenance. It may also cause thermal deformation and creep in some conditions.

Different from conventional optimization in structure, the current paper optimizes the flow path of the secondary air system and present a new rim seal method with auxiliary sealing holes transporting secondary sealing flow. The structure is shown in Fig. 1. By adding holes with an inclined angle in circumferential direction at a high radius of the static disk, the secondary flow of the combustion chamber（燃烧室 二股气流） are introduced through these holes to make cooling and sealing better at disc rim. The flow path of this new rim seal method are shown in Fig. 2.

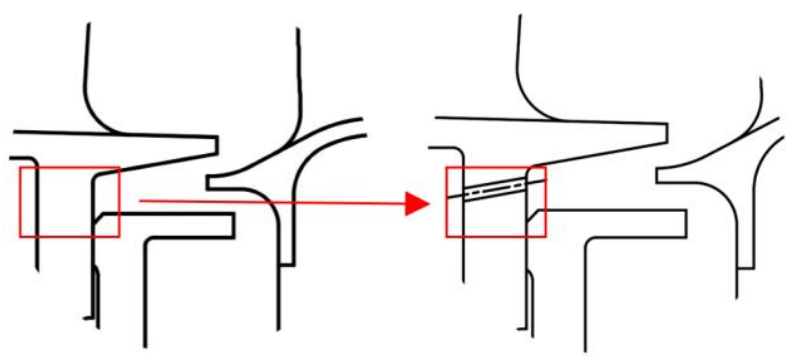

Fig. 1 rim seal with auxiliary sealing hole

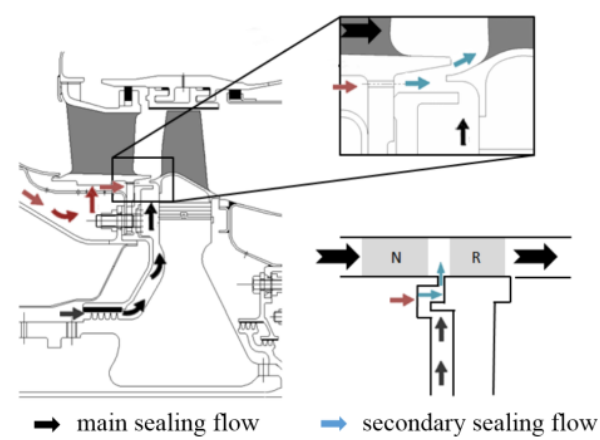

Fig. 2 flow path of rim seal with auxiliary sealing hole

This optimization idea comes from the real flow condition that exists in gas turbines. Clarks (Clarks 2016a, 2016b) investigated the leakage flow called Chordal Hindge Leakage (CHL) near the inner ring of the first turbine guide vane in a real engine shown in Fig. 3. Bunker (Bunker 2005) and Patinios (Patinios 2018) studied the similar flow structure. However, the leakage flow here only accounted for $10 \%$ of the total air flow bleed into the disk cavity, and have no tangential velocity component. The results of these studies show that this leakage air flow has no significant effect on engine efficiency, sometimes there are even bad effects.

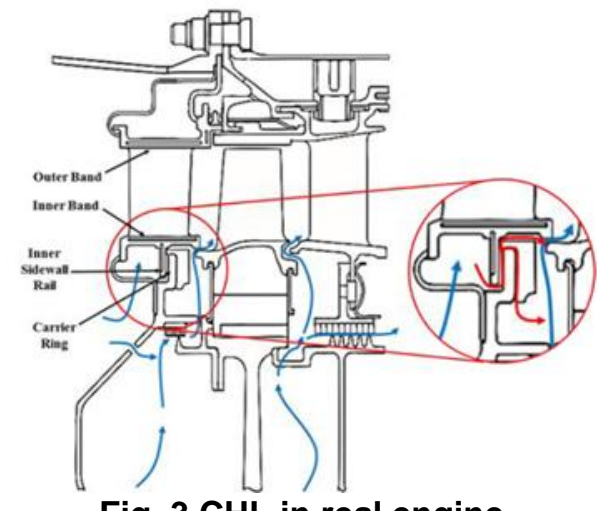

Fig. $3 \mathrm{CHL}$ in real engine

In the past two years, turbine designers has realized that this leakage flow (CHL) has the potential to improve the sealing efficiency of rim seal. Both Clarks (Clarks 2018) and Patinios (Patinios 2018) found that when the sealing air flow rate is constant, the excessive CHL flow will cause the "toroidal vortex" in disk cavity, which has negative effect on sealing efficiency. But under certain CHL flow rate, the Batchelor flow pattern inside the cavity can be maintained, and the sealing efficiency can be improved.

In a patent of PW (Durocher 2006) shown in Fig. 4, an inclined hole at high radial position is presented (No. 59). However, the inventor intended to use the impingement effect of cooling jet to cool the end wall of inner ring, and did not mention the effect of this inclined hole on the rim seal of this structure.

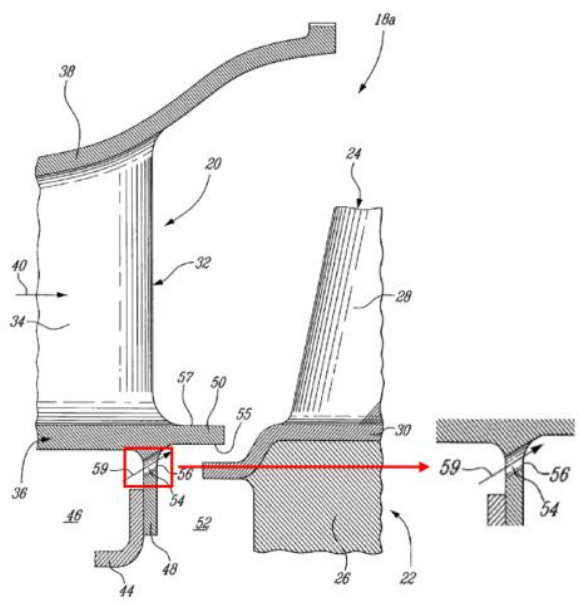

Fig. 4 a patent of PW

As is known to the author, the investigation of new control method and the use of inclined hole in high radial position to improve the rim seal efficiency is completely absent.

\section{CFD MODEL AND METHOD \\ CFD domain}

Based on the simple axial rim seal geometry, the CFD model are shown in Fig. 5. The model includes main flow and cavity flow, which can simulate the External Induced (EI) ingress and Rotational Induced (RI) ingress simultaneously.

The geometric parameters of the rim seal structure include: 
Table 1 domain geometry

rim seal inner radius (b)

height of mainstream channel (h)

axial clearance of gap $\left(\mathrm{S}_{\mathrm{c}, \mathrm{x}}\right)$

axial clearance of cavity $(\mathrm{S})$

The axial clearance ratio of the sealing gap $\mathrm{G}_{\mathrm{c}, \mathrm{x}}=\mathrm{S}_{\mathrm{c}, \mathrm{x}} / \mathrm{b}=0.0105$, axial clearance ratio of cavity $\mathrm{G}=\mathrm{S} / \mathrm{b}=0.105$. The vane is in stationary domain and the disc cavity is in rotational domain. The guide vane profile of high load and small aspect ratio (Sangan 2011) is selected. Due to symmetry, only a $11.25 \mathrm{deg}$ sector (1/32 of whole ring) is simulated.
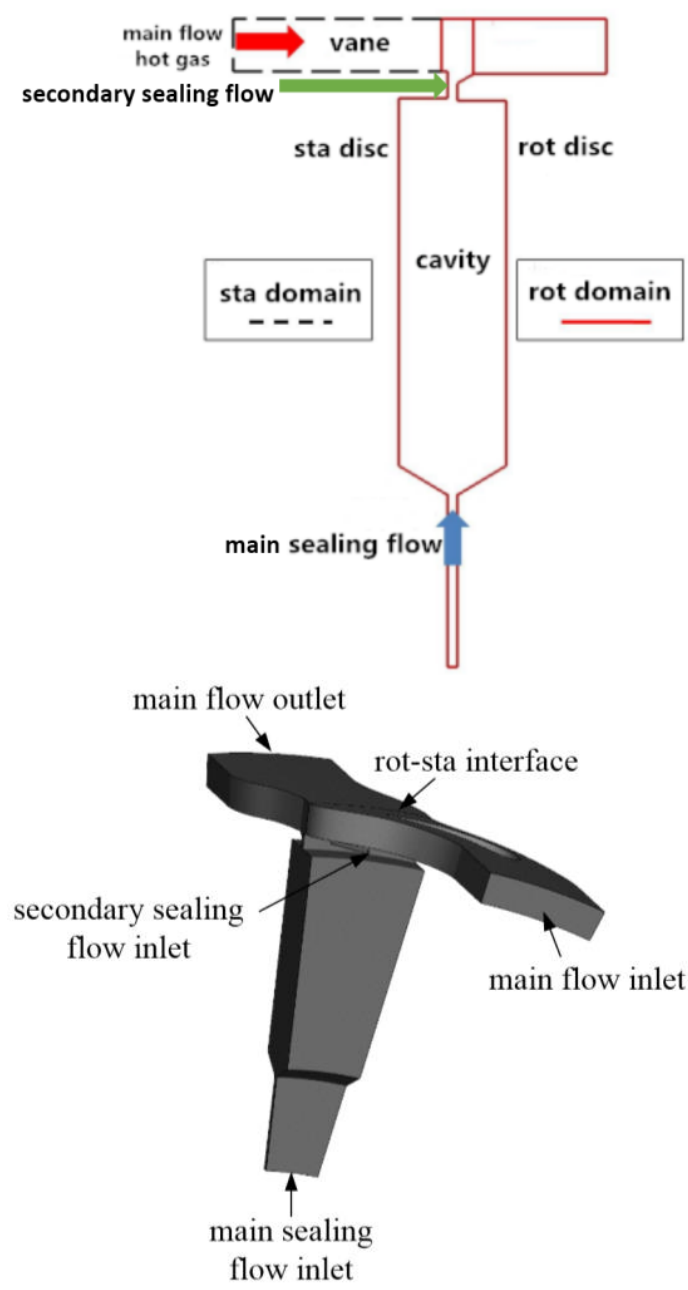

Fig. 5 CFD model

\section{CFD method and validation}

The ANSYS CFX 19.0 was used in the CFD process. The tracer gas concentration method was used in the study, and the trace gas concentration was used to indicate the degree of hot gas ingestion and the effect of rim seal. The CFD results are compared with experiment results by Kang Wu (Wu 2014).

The non-dimensional coefficient of static pressure $\left(c_{p}\right)$ is the main factor driving hot gas ingestion. The swirl ratio $(\beta)$ reflects the flow pattern in the disk cavity. The CFD results of $c_{\mathrm{p}}$ and $\beta$ agree well with the existing experiment results (Fig. $6,7)$, and the reliability of the method of model building, mesh generating and numerical scheme are verified.

$$
\begin{gathered}
c_{p}=\frac{p_{a}-p_{r e f}}{0.5 \rho \omega^{2} b^{2}} \\
\beta=\frac{v_{\varphi}}{\omega r}
\end{gathered}
$$

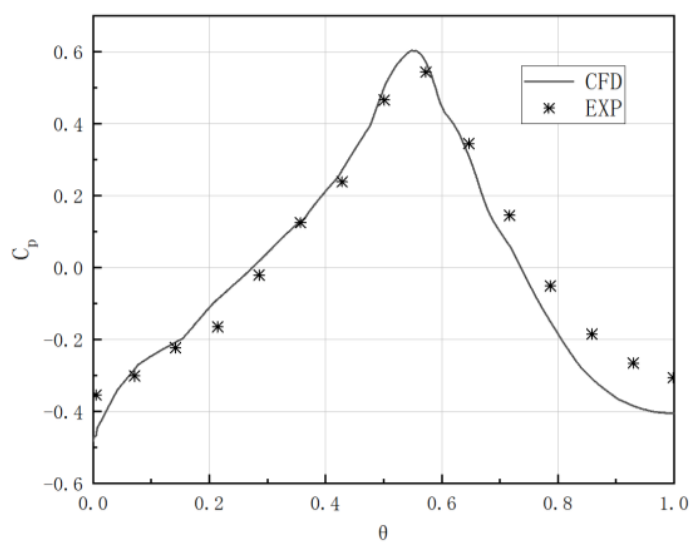

Fig. 6 compare $c_{p}$ between CFD and EXP

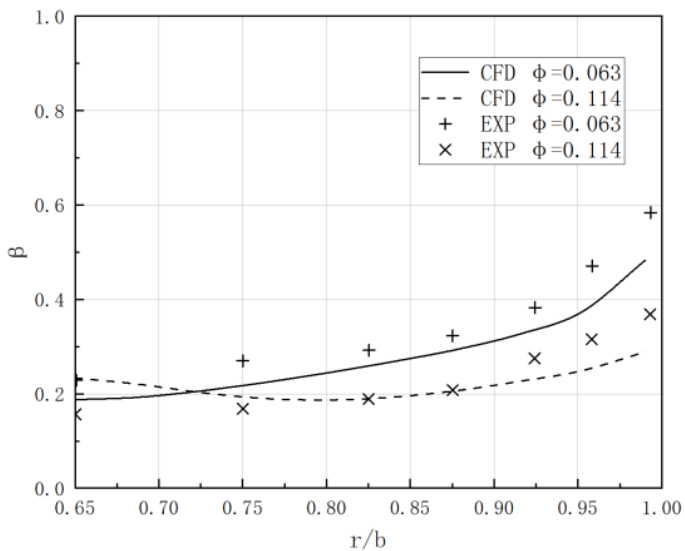

Fig. 7 compare $\beta$ between CFD and EXP

\section{Mesh and boundary condition}

The mesh was generated by ANSYS ICEM CFD 19.0. Fig. 8 shows the mesh detail near the disk rim. The mesh nodes in mainstream channel and cavity are perfectly matched to ensure the accuracy of the solution. Three geometries of different inclined angle (IA) of auxiliary sealing hole are shown in Fig. 9, and the mesh elements of these three geometries are between 3 3.5 million.

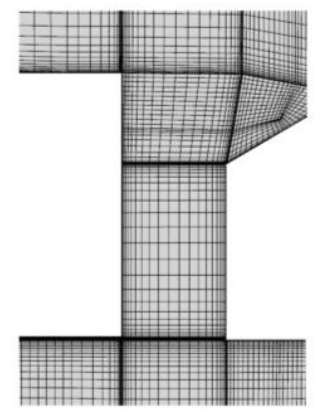

Fig. 8 mesh detail at disk rim 


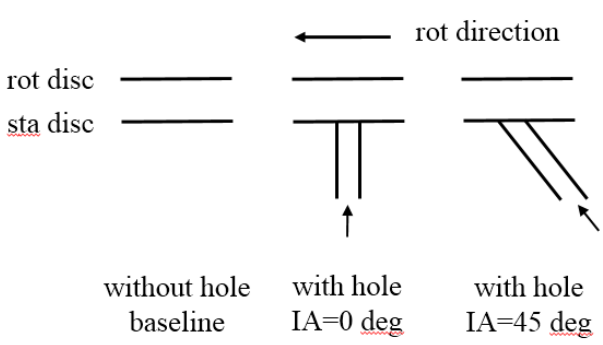

Fig. 9 three different geometries

In order to investigate the influence of inclined angle of auxiliary sealing hole and flow distribution of sealing flow, seven cases are calculated as below (IA=inclined angle of auxiliary sealing hole, $\mathrm{m}_{1}=$ main sealing flow from cavity entrance, $\mathrm{m}_{2}=$ secondary sealing flow from auxiliary sealing hole), the total sealing flow rate is remained equal for all cases, which account for $2.2 \%$ of the main flow rate. The baseline is case without the secondary sealing flow.

\section{Table 2 CFD cases}

\begin{tabular}{|c|c|c|}
\hline \multirow{3}{*}{ without hole (baseline) } & \\
\hline & IA (deg) & $\mathrm{m}_{1}: \mathrm{m}_{2}$ \\
\hline & - & - \\
\hline \multirow{2}{*}{ with hole } & 0 & $1: 1,2: 1,3: 1$ \\
\hline & 45 & $1: 1,2: 1,3: 1$ \\
\hline \multicolumn{3}{|c|}{ Table 3 CFD boundary conditions } \\
\hline \multirow{4}{*}{\multicolumn{2}{|c|}{$\begin{array}{l}\text { rotating speed }(\mathrm{N}, \mathrm{rpm}) \\
\text { non-dimensional sealing flow rate }\left(\Phi_{0}\right) \\
\text { Reynolds number of mainstream }\left(\operatorname{Re}_{\mathrm{x}}\right) \\
\text { Reynolds number of rotation }\left(\operatorname{Re}_{\psi}\right)\end{array}$}} & 3000 \\
\hline & & 0.063 \\
\hline & & $4.4 * 10^{5}$ \\
\hline & & $8.17 * 10^{5}$ \\
\hline
\end{tabular}

$$
\begin{gathered}
\Phi_{0}=\frac{m}{\mu b 2 \pi G_{c} \operatorname{Re}_{\phi}} \\
\operatorname{Re}_{x}=\frac{\rho \omega b}{\mu} \\
\operatorname{Re}_{\phi}=\frac{\rho \omega b^{2}}{\mu}
\end{gathered}
$$

\section{RESULTS AND DISCUSSION}

The effect of auxiliary sealing hole and inclined angle

In previous studies, the aim of rim seal design is to prevent hot gas ingest into cavity completely. It requires a large amount of sealing air, which will result in a significant drop in engine efficiency. Full-sealing is too consuming and not necessary, what important is to make sure that the temperature of key parts of disk cavity under the limitation. Therefore, the current paper investigate the sealing efficiency instead of minimum sealing flow rate.

The sealing efficiency is defined by concentration of a tracer gas added to the sealing air. It is accomplished by adding an additional variable and solving the transport equation of it in ANSYS CFX.

$$
\eta_{c}=\frac{c}{c_{a}}
$$

where $\mathrm{c}$ is the concentration of the tracer gas, and $\mathrm{c}_{\alpha}$ is the concentration of it in sealing air.

Figure 10 shows the sealing efficiency along radial direction on the stationary disk surface. The auxiliary sealing hole of $45 \mathrm{deg}$ is effective to improve sealing efficiency by $10 \%$ compared to the case without auxiliary sealing hole. However, the straight auxiliary sealing hole has a negative effect on sealing efficiency by $4 \%$ compared to the case without hole. These results can be confirmed by the sealing efficiency contour of the meridional plane in the disk cavity in Fig. 11.

When $m_{1}: m_{2}=2: 1$, the inclined hole of 45 deg have a positive effect on sealing efficiency. As the inclined direction of the hole is same to the rotational direction, the total temperature of the cooling air relative to the disk can be reduced by pre-swirl, which is also beneficial to cooling.

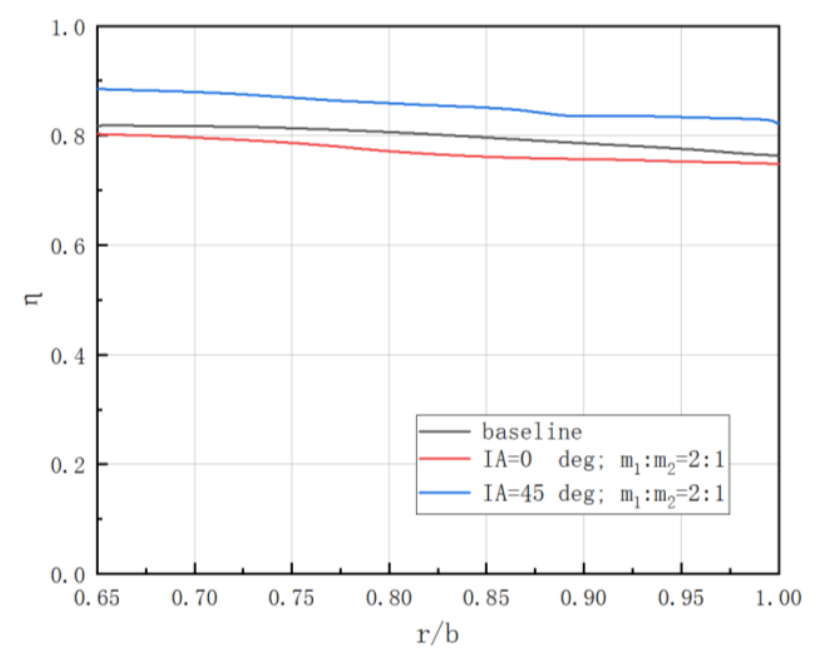

Fig. 10 sealing efficiency on sta disk of different IA

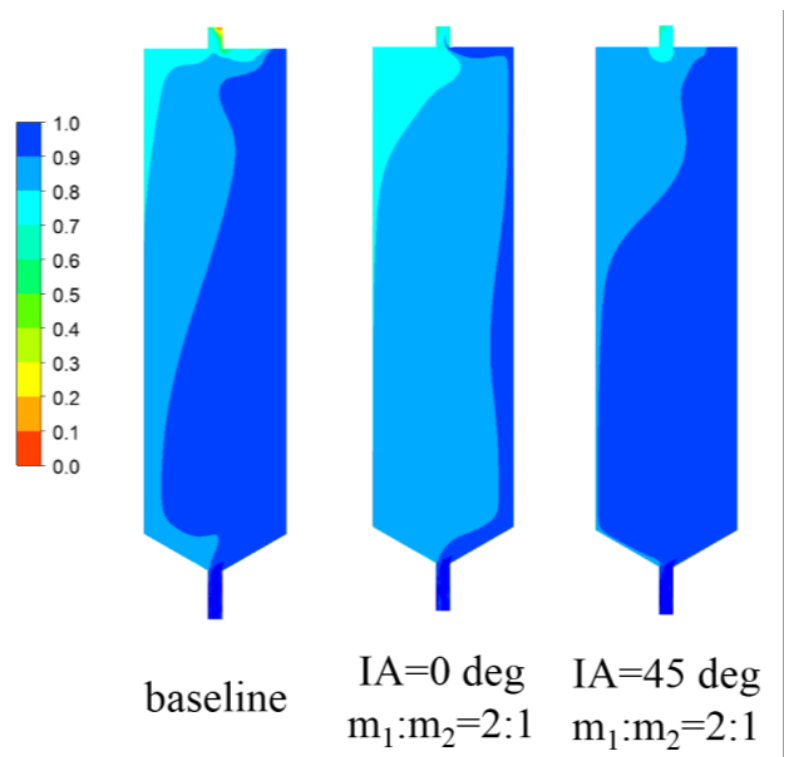

Fig. 11 sealing efficiency in disk cavity of different IA

Campbell's study (Campbell 1979) shows that the nonuniformity of pressure along the circumferential direction at disk rim helps to increase hot gas ingestion. The non- 
dimensional coefficient of static pressure is shown in Fig. 12. Hot gas will ingest into cavity at high pressure zone where $c_{p}>0$, and low pressure zone where $c_{p}<0$ is safe without the danger of hot gas ingestion. The inclined hole of $45 \mathrm{deg}$ has a minimum $\Delta \mathrm{c}_{\mathrm{p}}$, which is $8.15 \%$ less than the baseline, which can account for the trend of sealing efficiency.

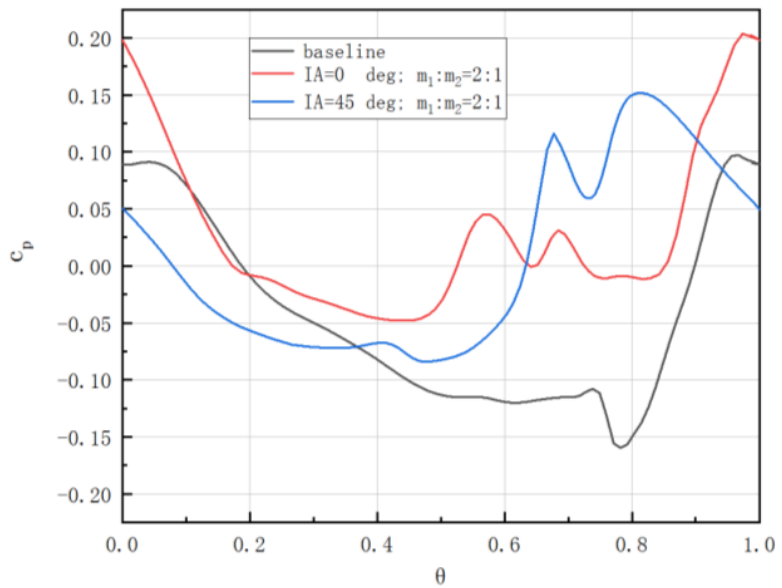

Fig. $12 c_{p}$ along circumference of disk rim

\section{The effect of flow distribution}

The whole sealing flow rate stay unchanged, and the secondary sealing flow rate account for $1 / 2,1 / 3$ and 1/4 respectively.

The investigation of sealing flow distribution has done on the optimized model with auxiliary sealing hole of $45 \mathrm{deg}$. Three cases $\left(\mathrm{m}_{1}: \mathrm{m}_{2}=1: 1,2: 1,3: 1\right)$ are calculated, showing that sealing flow distribution is also an important factor to sealing efficiency. The sealing efficiency is low when the mass flow of main sealing flow and secondary sealing flow are equal. When the ratio is increased to $2: 1$ and $3: 1$, the sealing efficiency is about $11 \%$ higher, and the difference between these two cases are much smaller.

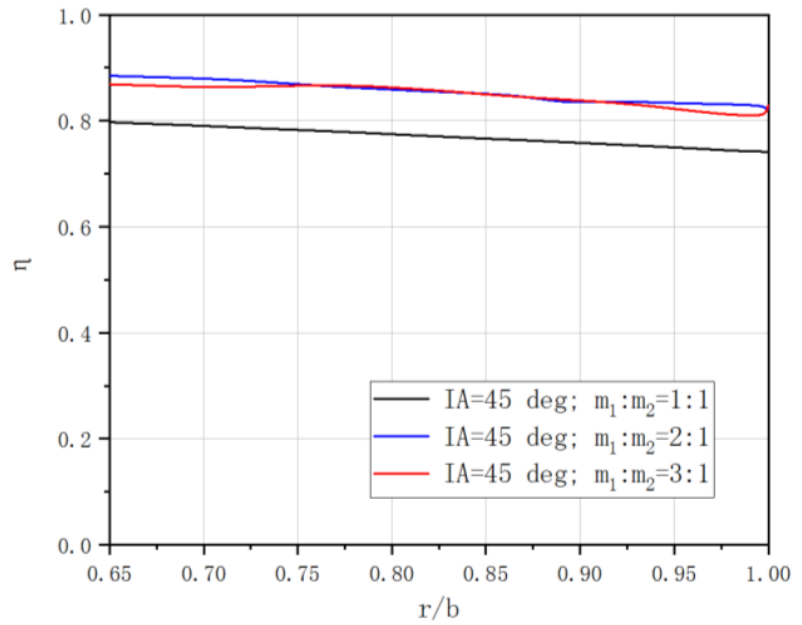

Fig. 13 sealing efficiency on sta disk of different sealing flow distribution
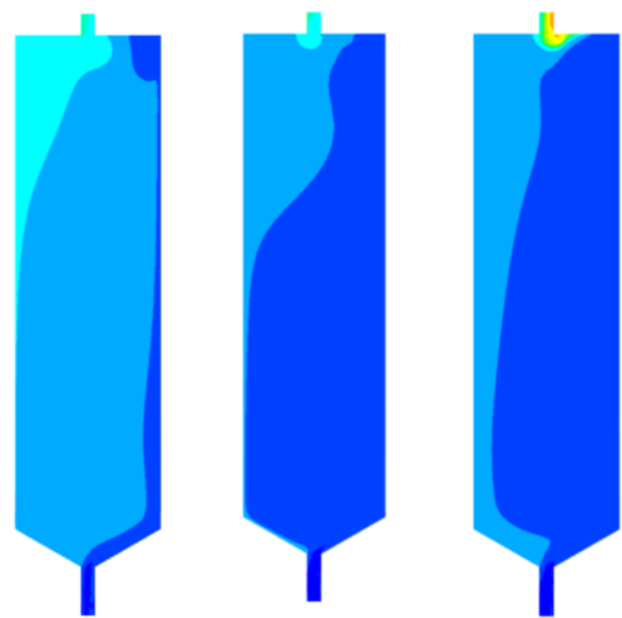

$$
\begin{array}{lll}
\mathrm{IA}=45 \mathrm{deg} & \mathrm{IA}=45 \mathrm{deg} & \mathrm{IA}=45 \mathrm{deg} \\
\mathrm{m}_{1}: \mathrm{m}_{2}=1: 1 & \mathrm{~m}_{1}: \mathrm{m}_{2}=2: 1 & \mathrm{~m}_{1}: \mathrm{m}_{2}=3: 1
\end{array}
$$

Fig. 14 sealing efficiency in disk cavity of different sealing flow distribution

\section{CONCLUSIONS}

The inclined auxiliary sealing air can improve the sealing efficiency, so that the air used for sealing from the secondary air system can be appropriately reduced to achieve the same sealing efficiency, which is beneficial to the aerodynamic efficiency of the turbine.

The new rim seal structure with auxiliary sealing hole is effective to improve sealing efficiency under certain conditions. Both inclined angle of auxiliary sealing hole and flow distribution of sealing flow have important impacts on rim seal efficiency.

1. The inclined sealing hole with the same direction of disc rotation has a positive effect on sealing efficiency, while the straight hole has a negative effect on it.

2. For inclined sealing hole, the sealing efficiency increases first and then remain almost unchanged as the flow distribution ratio $\mathrm{m}_{1} / \mathrm{m}_{2}$ increases.

3. The secondary sealing air from auxiliary sealing hole reduces hot gas ingestion by reducing the nonuniformity of pressure along circumferential direction.

The new structure of rim seal is easy to processing and manufacturing, which can acquire high rim seal efficiency without using complex structure. It provides a new idea to rim seal design in gas turbines.

\section{NOMENCLATURE}

$b \quad=$ inner radius of disc

$c=$ concentration of the tracer gas

$\eta \quad=$ sealing efficiency

$m \quad$ = mass flow rate

$\omega=$ rotating speed of the disc $(\mathrm{rad} / \mathrm{s})$

$p \quad=$ pressure

$c_{p} \quad=$ non-dimensional coefficient of pressure

$r \quad=$ radius

$v_{\varphi} \quad=$ velocity in tangential direction

$\rho \quad=$ density

$\beta \quad=$ swirl ratio 


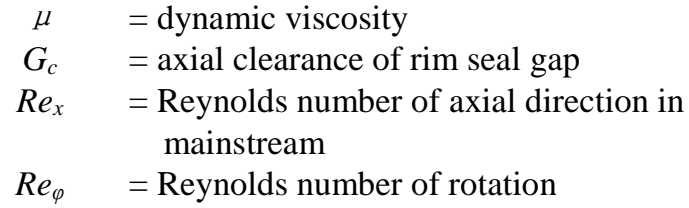

\section{REFERENCES}

Bunker, R.S., 2005. Turbine Cooling Design Analysis. Gas Turbine Handbook.

Campbell, D.A., 1978. Gas turbine disc sealing system design. AGARD Seal Technol. in Gas Turbine Eng. 16 p(SEE N 79-11056 02-07).

Clark, K., Barringer, M., Thole, K., Clum, C., Hiester, P., Memory, C. and Robak, C., 2016, June. Using a tracer gas to quantify sealing effectiveness for engine realistic rim seals. In ASME Turbo Expo 2016: Turbomachinery Technical Conference and Exposition (pp. V05AT15A034-V05AT15A034). American Society of Mechanical Engineers.

Clark, K., Barringer, M., Thole, K., Clum, C., Hiester, P., Memory, C. and Robak, C., 2017. Effects of purge jet momentum on sealing effectiveness. Journal of Engineering for Gas Turbines and Power, 139(3), p.031904.

Clark, K., Barringer, M., Johnson, D., Thole, K., Grover, E. and Robak, C., 2018. Effects of Purge Flow Configuration on Sealing Effectiveness in a Rotor-Stator Cavity. Journal of Engineering for Gas Turbines and Power, 140(11), p.112502.

Durocher, E., Synnott, R. and Blais, D., Pratt and Whitney Canada Corp, 2008. Airfoil platform impingement cooling. U.S. Patent 7,452,184.

Kang Wu, 2014. Research on the Mechanism of Sealing and Ingestion in Gas Turbine Rotor-Stator Rim (Doctoral dissertation, Tsinghua University)

Li, J., Gao, Q., Li, Z. and Feng, Z., 2016. Numerical investigations on the sealing effectiveness of turbine honeycomb radial rim seal. Journal of Engineering for Gas Turbines and Power, 138(10), p.102601.

Patinios, Marios \& L. Ong, Irvin \& Scobie, James \& D. Lock, Gary \& M. Sangan, Carl. (2018). Influence of Leakage Flows on Hot Gas Ingress. Journal of Engineering for Gas Turbines and Power. 141. 10.1115/1.4040846.

Sangan, C.M., 2011. Measurement of ingress through gas turbine rim seals (Doctoral dissertation, University of Bath).

Sangan, C.M., Pountney, O.J., Scobie, J.A., Wilson, M., Owen, J.M. and Lock, G.D., 2013. Experimental Measurements of Ingestion Through Turbine Rim Seals-Part III: Single and Double Seals. Journal of Turbomachinery, 135(5), p.051011.

Sangan, C.M., Scobie, J.A., Owen, J.M., Lock, G.D., Tham, K.M. and Laurello, V.P., 2014. Performance of a finned turbine rim seal. Journal of Turbomachinery, 136(11), p.111008.
Scobie, J.A., Sangan, C.M., Owen, J.M. and Lock, G.D., 2016. Review of ingress in gas turbines. Journal of Engineering for Gas Turbines and Power, 138(12), p.120801.

Scobie, J.A., Teuber, R., Li, Y.S., Sangan, C.M., Wilson, M. and Lock, G.D., 2016. Design of an improved turbine rim-seal. Journal of Engineering for Gas Turbines and Power, 138(2), p.022503. 